\title{
PENGEMBANGAN RUMAH SAMPAH BERBASIS SEKOLAH (RSBS) UNTUK PEMBIASAAN KARAKTER PEDULI LINGKUNGAN ANAK USIA DINI DI RA AL-IKHLAS KECAMATAN PAGERAGEUNG KABUPATEN TASIKMALAYA
}

\author{
Edi Hendri Mulyana ${ }^{1}$, Hodidjah ${ }^{2}$, Laila Sari Ramadhan ${ }^{3}$ \\ ${ }^{1}$ Program Studi PGPAUD UPI Kampus Tasikmalaya \\ ${ }^{2}$ Program Studi PGSD UPI Kampus Tasikmalaya \\ ${ }^{3}$ Program Studi PGPAUD UPI Kampus Tasikmalaya
}

Email: edihm@upi.edu

(Received: Mei 2017; Accepted: Mei 2017; Published: Juni 2017)

\begin{abstract}
This research is motivated by the existence of School Based Trash program (RSBS) in RA Al-Ikhlas for character habituation in early childhood. The purpose of this research is to develop the RSBS program consisting of the development of RSBS organization structure and program activities of RSBS, developer based on good organizational structure and Law no. 18 of 2008 on waste management. The method used is the method of Design Based Research (DBR) with the steps: 1) analysis of practical problems by researchers and practitioners. 2) development of solutions with a theoretical framework. 3) evaluation and testing of solutions in practice. 4) documentation and reflection to produce "design principle", it can be taken some conclusions. The sample used in this study is a saturated sample of 21 people. Data collection tools include interview guides, checklists (checklists) and observation sheets. The results show that the development of RSBS program has resulted in the organization structure of RSBS and RSBS activities. The developed RSBS program has enhanced the habituation of environmentally-caring characters, before the $14.3 \%$ and $14.7 \%$ of the developed environmentally friendly MB (SBS) environmental developers and $85.7 \%$ BB (Not Developed) study develop. After revision twice as much as environmental care characters increased by $47.6 \%$ BSB (Very Good Developing), $47.6 \%$ BSH (Growing Up Expectations), and 4.8\% MB (Beginning).
\end{abstract}

Keywords: RSBS Program, Habitual Caring for the Environment, Early Childhood

\begin{abstract}
ABSTRAK
Penelitian ini dilatarbelakangi oleh adanya program Rumah Sampah Berbasis Sekolah (RSBS) di RA Al-Ikhlas untuk pembiasaan karakter pada anak usia dini. Tujuan penelitian ini untuk mengembangkan program RSBS yang terdiri dari pengembangan struktur organisasi RSBS dan kegiatan program RSBS, pengembangan didasarkan pada kaidah struktur organisasi yang baik dan UU No. 18 tahun 2008 tentang pengelolaan sampah. Metode yang digunakan ialah metode Design Based Research (DBR) dengan tahapan: 1) melakukan identifikasi dan analisis masalah yang dilakukan peneliti dan praktisi secara kolaboratif. 2) mengembangkan solusi yang didasarkan pada patokan teori, design principle yang ada dan inovasi teknologi. 3) proses berulang untuk menguji dan memperbaiki solusi secara praktis 4) melakukan refleksi untuk menghasilkan design principle serta meningkatkan implementasi dari solusi secara paraktis, maka dapat diambil beberapa simpulan. Sampel yang digunakan dalam penelitian ini ialah sampel jenuh yang berjumlah 21 orang. Alat pengumpuan data berupa pedoman wawancara, checklist (daftar cek) dan lembar observasi.Hasil penelitian menunjukkan pengembangan program RSBS telah menghasilkan struktur organisasi RSBS dan kegiatan RSBS.Program RSBS yang dikembangkan telah meningkatkan pembiasaan karakter peduli lingkungan, sebelum dikembangkan peneliti karakter peduli lingkungan MB (Mulai Berkembang) 14.3\% dan BB (Belum Berkemabang) 85.7\%. Setelah dilakukan revisi sebanyak dua kali karakter peduli lingkungan mengalami peningkatan dengan 47.6\% BSB (Berkembang Sangat Baik), 47.6\% BSH (Berkembang Sesuai Harapan), dan 4.8\% MB (Mulai Berkembang).
\end{abstract}

Kata kunci: Program RSBS, Pembiasaan Karakter Peduli Lingkungan, Anak Usia Dini 


\section{PENDAHULUAN}

Dewasa ini sistem pendidikan di Indonesia lebih banyak dibangun bukan dari kesadaran pembangunan masyarakat baru secara revolusioner dan visioner.Banyak sekolah yang mengunggulkan program yang berasal dari kebutuhan orang dewasa terhadap anaknya tanpa menimbang pertumbuhan dan perkembangan yang harus dilalui oleh anak.

Persoalan krisis global semakin komplek dan multidimensional salah satu masalah serius adalah kondisi lingkungan hidup yang melibatkan cara pandang manusia modern terhadap alam. Pada gilirannya memaksa para ahli pendidikan mengkonstruksi ulang kurikulum pendidikan, misalnya dengan mengintroduksi konsep keanekaragaman hayati dan kesadaran ekosistem.

Krisis global yang dihadapi yakni pencemaran lingkungan yang berasal dari sampah. Menurut UURI No.18 Tahun 2008 tentang Pengelolaan Sampah BAB I Pasal 1 menyatakan bahwa "sampah adalah sisa kegiatan sehari-hari manusia atau proses alam yang berbentuk padat." Pertambahan penduduk, perubahan konsumsi masyarakat dan kurangnya pengelolaan sampah menjadi faktor penyebab pencemaran lingkungan yang ditimbulkan oleh sampah.

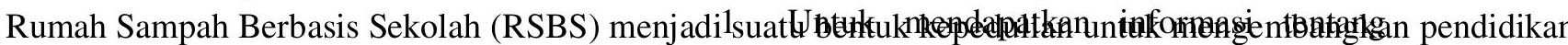
agar masyarakat mendapat keuntungan ekonomi dari menabung sampah, sedangkan Rumah Sampah Berbasis Sekolah mengedepankan edukasi untuk seluruh elemen sekolah dan keuntungan nilai ekonomi hanya sebagai nilai tambahan.

Pogram RSBS untuk anak usia dini sangatlah penting karena berdasarkan hasil penelitian Osbora,White dan Bloom (dalam Apriana, 2009) diketahui bahwa perkembangan intelektual manusia pada usia 4 tahun sudah mencapai $50 \%$, pada usia 8 tahun mencapai $80 \%$ dan mencapai $100 \%$ pada usia 18 tahun. Dari hasil penelitian ini, kita tahu bahwa dominasi perkembangan otak anak terjadi pada masa golden age, sehingga pada masa ini sangat tepat menumbuhkan karakter sedari dini, terutama karakter peduli lingkungan.
Namun sistem dari program RSBS untuk anak usia dini belumlah sempurna. Program RSBS untuk Anak Usia Dini saat ini yakni memilah sampah organik dan anorganik serta menyetorkan sampah produktif ke sekolah, belum adanya indikator keberhasilan atau capaian karakter peduli lingkungan yang diharapkan.

Berdasarkan latar belakang yang dikemukakan maka dapat dirumuskan permasalahan penelitian yaitu:

1. Bagaimana Rumah Sampah Berbasis Sekolah (RSBS) sebelum dilakukan pengembangan di RA Al-Ikhlas Kecamatan Pagerageung Kabupaten Tasikmalaya?

2. Bagaimana rancangan pengembangan Rumah Sampah Berbasis Sekolah (RSBS) di RA Al-Ikhlas Kecamatan Pagerageung Kabupaten Tasikmalaya?

3. Bagaimana uji coba program Rumah Sampah Berbasis Sekolah (RSBS) di RA Al-Ikhlas Kecamatan Pagerageung Kabupaten Tasikmalaya?

4. Bagaimana produk akhir pengembangan Rumah Sampah Berbasis Sekolah (RSBS) di RA Al-Ikhlas Kecamatan Pagerageung Kabupaten Tasikmalaya?

Adapun tujuan penelitian ini adalah: program Rumah Sampah Berbasis Sekolah (RSBS) yang telah diterapkan di RA Al-Ikhlas Kecamatan Pagerageung Kabupaten Tasikmalaya.

2. Untuk menghasilkan rancangan program Rumah Sampah Berbasis Sekolah (RSBS) di RA Al-Ikhlas Kecamatan Pagerageung Kabupaten Tasikmalaya.

3. Untuk mendapatkan gambaran efektivitas program Rumah Sampah Berbasis Sekolah (RSBS) di RA Al-Ikhlas Kecamatan Pagerageung Kabupaten Tasikmalaya.

4. Untuk menghasilkan desain akhir program Rumah Sampah Berbasis Sekolah (RSBS) di RA Al-Ikhlas Kecamatan Pagerageung Kabupaten Tasikmalaya. 


\section{TINJAUAN PUSTAKA}

Kehidupan manusia tidak terlepas dari sampah, "sampah adalah barang-barang buangan atau kotoran, seperti daun-daun kering, kertas-kertas kotor dan sebagainya" (Anwar, 200, hlm. 391). Undang-Undang No. 18 Tahun 2008 tentang Pengelolaan Sampah menyatakan "sampah adalah sisa kegiatan sehari-hari manusia atau proses alam yang terbentuk padat atau semi padat berupa zat organik atau anorganik bersifat dapat terurai atau tidak dapat terurai yang dianggap sudah tidak berguna lagi dan dibuang ke lingkungan".

\subsection{Pengelolaan Sampah Berdasarkan UURI No.18 Tahun 2008}

Pengelolaan sampah sangatlah penting untuk dilakukan. Pengelolaan sampah juga dapat dilakukan di sekolah terutamabagi anak usia dini agar menumbuhkan rasa cinta terhadap lingkungan, terutama anak perkotaan. Hal ini sejalan dengan Collado, dkk. (2015, hlm. 73) "For urban children, daily contact with nature appears to be an effective means toward encouraging pro-environmental attitudes." Pengelolaan sampah di Indonesia di atur dalam Undang-Undang RI No. 18 tahun 2008, UURI No. 18 mengatur ketentuan umum, ruang lingkup, tugas dan wewenang pemerintah sampai ke penyelenggaraan pengelolaan sampah.Undang-undang pengelolaan sampah yang dapat dilakukan anak usia dini ialah UURI No. 18 Tahun 2008 BAB VI tentang Penyelenggaraan Pengelolaan Sampah, Paragraf Kesatu tentang Pengurangan Sampah Pasal 20 Ayat 1 huruf a,b dan c dan Paragraf Kedua tentang Penanganan Sampah Pasal 22 Ayat 1 huruf a dan $b$ menjadi landasan perancangan program RSBS yang berbunyi sebagai berikut.

Paragraf Kesatu

Pengurangan Sampah Pasal 20

1. Pengurangan sampah sebagaimana dimaksud dalam Pasal 19 huruf a meliputi kegiatan:

a. Pembatasan timbulan sampah; b. Pendaur ulang sampah; dan/atau

c. Pemanfaatan kembali sampah

\section{Paragraf Kedua \\ Penanganan Sampah \\ Pasal 22}

1. Kegiatan penanganan sampah sebagaimana dimaksud dalam Pasal 19 huruf b meliputi:

a. Pemilahan dalam bentuk pengelompokkan dan pemisahan sampah sesuai dengan jenis, jumlah dan/atau sifat sampah;

b. Pengumpulan dalam bentuk pengambilan dan pemindahan sampah dari sumber sampah ke tempat penampungan sementara atau tempat pengolahan sampah terpadu.

\subsection{Aspek-Aspek Organisasi}

Aspek-aspek dalam organisasi adalah komponen-komponen yang harus ada dalam suatu organisasi. Keberadaan komponen ini sebagai pilar suatu organisasi karena jika salah satu komponen organisasi tidak berfungsi, maka organisasi akan berjalan pincang atau sama sekali tidak berjalan.

O' Connor, T. (dalam Tim Dosen Administrasi Pendidikan UPI, 2012, hlm. 70) mengungkapkan organisasi setidaknya harus memiliki empat komponen utama yang terdapat pada gambar 2.1.yakni:

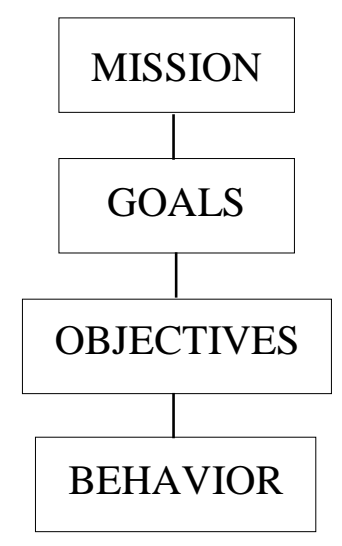

Aspek-aspek Organisasi 


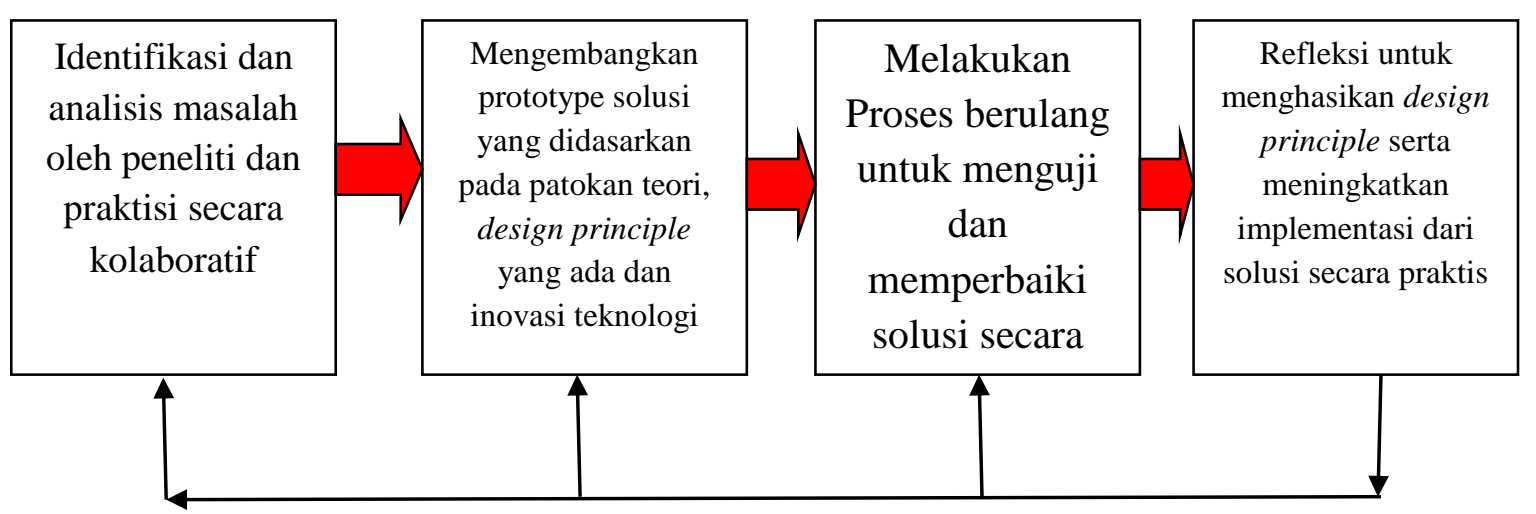

Aspek-aspek Organisasi

a. Mission adalah alasan utama keberadaan suatu organisasi.

b. Goals adalah tujuan-tujuan umum atau tujuan-tujuan divisi-divisi fungsional organisasi yang dihubungkan dengan stakeholder organisasi.

c. Objectives adalah hasil/sasaran yang spesifik, terukur dan terkait dengan tujuan. Sasaran ini biasanya mencantumkan batasan waktu dan siapa yang bertanggungjawab terhadap sasaran tersebut.

d. Behavior mengacu pada produktivitas dari tugas-tugas rutin pegawai. Pertanggungjawaban perilaku dalam pencapaian tujuan merupakan fungsi personalia.

Keberadaan suatu organisasi tidak akan lepas dari keempat komponen. Jika suatu organisasi tidak memiliki sasaran yang harus dicapai oleh setiap orang dalam organisasi, maka mereka akan kebingungan mengenai apa dan bagaimana perilaku yang harus dimunculkan oleh pegawai. Jika suatu organisasi tidak memiliki misi yang harus dilakukan, maka orang-orang dalam organisasi akan kebingungan mengenai tujuan apa yang harus dicapai oleh organisasi. Hal ini menunjukkan bahwa empat komponen organisasi tersebut saling terikat satu samalain, sehingga tidak akan berfungsi suatu organisasi jika salah satu komponen hilang.

\section{METODE}

Metode penelitian yang digunakan dalam penelitian ini adalah metode design based research $(D B R)$. Barab and Squire (dalam Herington. et al, 2007) "Design Based Reseach didefinisikan sebagai serangkaian pendekatan, dengan maksud menghasilkan teori-teori baru, artefak, dan praktik yang menjelaskan dan berpotensi berdampak belajar dan pembelajaran naturalistic"

Tahap pertama merupkan tahap analisis data dilapangan dengan melaukan wawancara kepada guru kelas, studi dokumentasi dan observasi performance karakter peduli lingkungan anak.Tahap kedua pengembangan program RSBS yakni mengembangkan organisasi RSBS dan kegiatan RSBS kemudian divalidasi oleh ahli.Setelah divalidasi dilakukan uji coba I dan di revisi kemudian dilakukan uji coba II.Dan tahap empat hasil akhir diperoleh organisasi dan kegiatan RSBS yang dapat digunakan di Lembaga PAUD.

\section{TEMUAN DAN PEMABAHASAN}

\subsection{Hasil Identifikasi dan Analisis Masalah}

\section{Pengelolaan Sampah dan Karakter Peduli Lingkungan terhadap Lingkungan di RA Al-Ikhlas}

Hasil wawancara dengan guru kelas, program RSBS di RA Al-Ikhlas hanya sebatas membuang sampah pada tempatnya dan membawa sampah produktif dari rumah ke sekolah untuk disetorkan ke rumah sampah.Studi dokumentasi yang dilakukan di 
RA Al-Ikhlas terdapat dokumen berupa catatan penyetoran sampah yang dilakukan anak. Observasi ketersediaan fasilitas pendukung program RSBS di RA Al-Ikhlas bahwa alat kebersihan, rumah sampah dan tong sampah yang menunjang program RSBS namun belum ada himbauan "buang sampah pada tempatnya", tenpat pengelolaan sampah organik, kantung kain dan tempat makan anak sebagai upaya pengurangan sampah.Peneliti melakukan observasi performance karakter peduli lingkungan anak, 12 dari 21 anak memperoleh kriteria BB (Belum Berkembang) dengan persentase $57.14 \%$ dan 9 anak memperoleh kriteria MB (Mulai Berkembang) dengan persentase $42.85 \%$

\subsection{Pengembangan Rancangan RSBS RA Al-Ikhlas}

Pengembangan Rancangan RSBS terdiri dari pengembangan organisasi RSBS dan kegiatan RSBS.Rancangan organisasi berdasarkan teori O'Connor, $\mathrm{T}$ (dalam Tim Dosen Administrasi Pendidikan UPI, 2012, hlm.70) menjelaskan tentang aspek-aspek organisasi yang terdiri dari mission, goals, objectives, dan behavior.Pengembangan kegiatan RSBS berdasrakan prinsip pengelolaan sampah 4M (dalam Tresnawati, T, 2016, hlm. 58) yang terdiri dari mengurangi (reduce), mengganti (replace), menggunakan kembali (reuse), dan mengolah kembali (recycle).

\subsection{Proses Berulang untuk Menguji dan Memperbaiki Solusi secara Praktis}

Peneliti melakukan uji validasi ahli dan proses berulang rancangan pengembangan di RA Al-Ikhlas. Tujuannya yaitu untuk mengetahui apakah rancangan struktur organisai dan rancangan kegiatan RSBS layak digunakan atau harus diperbaiki.Uji validasi rancangan stuktur organisasi dilakukan kepada satu orang dosen dan satu orang Pembina RSBS yang berkompeten dalam bidangnya.Sedangkan rancangan kegiatan RSBS di validasi oleh kepala sekolah RA AlIkhlas. Kegiatan RSBS yang semula berdasarkan pengelolaan sampah $4 \mathrm{M}$ menjadi berdasarkan UURI No.18 Tahun 2008 tentang Pengelolaan Sampah, sehingga menjadi kegiatan Penyuluhan, Rumah Sampah dan NYAKAR (NYAAh KA Runtah).

Peneliti melakukan dua kali uji coba pada performance karakter peduli lingkungan anak RA Al-Ikhlas. Uji coba I, 10 dari 21 anak memperoleh kriteria BSB (Berkembang Sangat Baik) dengan persentase $47.6 \%$ dan 11 anak memperoleh kriteria BSH (Berkembang Sesuai Harapan) dengan persentase $52.3 \%$. Uji coba II, 18 anak memperoleh kriteria BSB (Berkembang Sangat Baik) dengan persentase $85.71 \%$ dan 3 anak memperoleh kriteria BSH (Berkembang Sesuai Harapan) dengan persentase $14.28 \%$

\subsection{Melakukan Refleksi untuk Menghasilkan Design Principle serta Meningkatkan Implementasi dari Solusi secara Praktis}

Pada tahap selanjutnya program RSBS berhasil dikembangkan dengan beberapa revisi.

\section{KESIMPULAN}

Berdasarkan hasil penelitian dan pegembangan program RSBS untuk pembiasaan karakter peduli lingkungan anak usia dini di RA Al-Ikhlas Kecamatan Pageragueng Kabupaten Tasikkmalaya berupa pengembangan struktur organisasi dan kegiatan program RSBS dengan metode $D B R$ (Desigen-Based-Research) dengan tahapan: 1) melakukan identifikasi dan analisis masalah yang dilakukan peneliti dan praktisi secara kolaboratif. 2) mengembangkan solusi yang didasarkan pada patokan teori, design principle yang ada dan inovasi teknologi. 3) proses berulang untuk menguji dan memperbaiki solusi secara praktis 4) melakukan refleksi untuk menghasilkan design principle serta meningkatkan implementasi dari solusi secara paraktis, maka dapat diambil beberapa simpulan.

1. Sebelum dilaksanakan pengembangan RSBS RA Al-Ikhlas Kecamatan Pagerageung, program RSBS telah dilaksanakan untuk pembiasaan karakter 
peduli lingkungan. Program RSBS yang dilaksanakan di RA Al-Ikhlas hanya sebatas menyediakan alat kebersihan, tong sampah organik dan anorganik serta Rumah Sampah sebagai tempat penampungan sampah anorganik produktif yang dibawa anak dari rumah ke sekolah. Yayasan dan sekolah setuju jika Program RSBS dikembangkan agar penanaman karakter peduli lingkungan lebih bermakna dan menyeluruh, tidak hanya memilah sampah tapi anak bisa mengurangi dan memanfaatkan sampah.

2. Tahap awal pengembangan dihasilkan rancangan yang terdiri dari struktur organisasi dengan mengacu pada aspekaspek organisasi O'Connor, $\mathrm{T}$ yakni mission, goals, objectives, dan behavior. Kegiatan RSBS mengacu kepada pengolahan sampah 4M yakni mengurangi (reduce), menggantikan (replace), menggunakan kembali (reuse), mengolah kembali (recycle). Disusunlah rancangan dalam bentuk rancangan struktur organisasi program RSBS dan rancangan kegiatan program RSBS untuk pembiasaan karakter peduli lingkungan anak usia dini.

3. Pada implementasi berdasarkan hasil validasi terhadap rancangan program RSBS rancangan mengalami revisi. Rancangan struktur organisasi dirancang ulang dan rancangan kegiatan RSBS awalnya mengacu pada 4M menjadi mengacu kepada UURI No. 18 Tahun 2008 tentang Pengelolaan Sampah Paragraf Kesatu tentang Pengurangan Sampah Pasal 20 Ayat 1 huruf a,b dan c, dan Paragraf Kedua tentang Penanganan Sampah Pasal 22 Ayat 1 huruf a dan b. Pada uji coba I struktur organisasi RSBS dapat digunakan denganbaik oleh sekolah dan program kegiatan RSBS yakni penyuluhan, rumah sampah dan NYAKAR dilakukan sehingga didapat nilai karakter peduli lingkungan anak dengan 10 dari 21 anak memperoleh kriteria BSB dengan persentase $47.6 \%$, kriteria BSH diperoleh 11 anak dengan persentase $52.3 \%$. Selanjutnya program RSBS mengalami revisi II sebelum dilakukan ui coba II. Revisi II lebih kepada teknis kegiatan program RSBS. Uji coba II dilakukan dengan hasil yang mengalami peningkatan baik. Karakter peduli lingkungan uji coba II mengalami peningkatan dengan 18 dari 21 anak memperoleh BSB dengan presentase $85.71 \%$ dengan kenaikan $38.11 \%$ pada uji coba I, BSH diperoleh 3 anak dengan persentase $14.28 \%$.

4. Pada penelitian ini diperoleh hasil akhir berupa struktur organisasi RSBS dan kegiatan RSBS untuk pembiasaan karakter peduli lingkungan anak usia dini.

\section{SARAN}

Dengan mengidentifikasi pengalaman selama melaksanakan penelitian untuk pengembangan program RSBSuntuk pembiasaan karakter peduli lingkungan dan hasil penelitian, peneliti memberikan beberapa saran berikut:

1. Untuk para guru dan mahasiswa calon guru, agar lebih membantu mengembangkan program RSBS dari segi pengembangan organisasi dan kegiatan RSBS.

2. Untuk kepala sekolah diharapkan memiliki karakter peduli lingkungan sehingga dapat memberikan instruksi kepada guru dan elemen sekolah untuk memberikan pembiasaan karakter peduli lingkungan kepada anak dan mengkoordinasikan kepada orangtua supaya pendidikan yang diberikan disekolah dapat diberikan dirumah sehingga sejak usia dini anak mengembangkan karakter peduli lingkungan.

3. Untuk pemerintah khususnya Dinas Pendidikan, diharapkan program RSBS yang dikembangkan menjadi salah satu acuan untuk menerapkan pengelolaan sampah di sekolah dan peneliti berharap dapat dijadikan kebijakan di sekolah khususnya Lembaga PAUD sehingga 
seluruh Lembaga PAUD melaksanakan program RSBS.

4. Untuk peneliti selanjutnya, diharapkan untuk lebih mengembangkan program RSBS terutama kegiatan RSBS yang dapat membantu sekolah mengelola sampah sekaligus mengembangkan karakter peduli lingkungan kepada anak.

\section{DAFTAR PUSTAKA}

Anwar, Dessy.(2001). Kamus Lengkap Bahasa Indonesia. Surabaya: Karya Abditama

Apriana, R. (2009). Hubungan Pendidikan Anak Usia Dini (PAUD) Dengan Perkembangan Kognitif Anak Usia Dini Prasekolah di Kelurahan Tinjomoyo Kecamatan Banyumanik. Skripsi Tidak diterbitkan. Semarang: Program Studi Ilmu Keperawatan. Fakultas Kedokteran Universitas Diponegoro

Collado, S., dkk.(2015). Effect of frequency and mode of contact with nature on children's self-reported ecological behaviors.Journal of Environmental Psychology, 41, 65-73.

Herrington, J. et.al.. (2007). Design-based research and doctoral students: Guidelines for preparing a dissertation. Journal: ECU Publications.

Tim Dosen Administrasi Pendidikan Universitas Pendidikan Indonesia.(2012). Manajemen Pendidikan.Bandung: ALFABETA.

Tresnawati, T. (2016).1001 Cara Daur Ulang Sampah. Bandung: CV Media Sarana Cerdas.

Undang-Undang Republik Indonesia Nomor 18 Tahun 2008 tentang Pengelolaan Sampah 